Meta

Journal des tradlucteurs

Translators' Journal

\title{
Au pilori (suite)
}

\section{Paul A. Horguelin}

Volume 14, numéro 4, décembre 1969

URI : https://id.erudit.org/iderudit/003106ar

DOI : https://doi.org/10.7202/003106ar

Aller au sommaire du numéro

Éditeur(s)

Les Presses de l'Université de Montréal

\section{ISSN}

0026-0452 (imprimé)

1492-1421 (numérique)

Découvrir la revue

Citer cet article

Horguelin, P. A. (1969). Au pilori (suite). Meta, 14(4), 223-223.

https://doi.org/10.7202/003106ar

Ce document est protégé par la loi sur le droit d'auteur. L'utilisation des services d'Érudit (y compris la reproduction) est assujettie à sa politique d'utilisation que vous pouvez consulter en ligne.

https://apropos.erudit.org/fr/usagers/politique-dutilisation/
Cet article est diffusé et préservé par Érudit.

Érudit est un consortium interuniversitaire sans but lucratif composé de l'Université de Montréal, l'Université Laval et l'Université du Québec à Montréal. Il a pour mission la promotion et la valorisation de la recherche. https://www.erudit.org/fr/ 


\section{COMMIS (VOYAGEUR OU PAS)}

Monsieur Guy Hurtubise, directeur de la mise en marché à l'Institut canadien de la plomberie et du chauffage, nous a fait parvenir copie d'une lettre qu'il a adressée au ministère du Commerce et du Développement de l'Ontario et dans laquelle il s'insurge contre l'emploi du terme « commis voyageur » par l'Association des commis voyageurs du Canada. "Ce terme de commis est non seulement périmé depuis au moins vingt ans mais il a même pris un sens péjoratif! » Notre lecteur nous demande ce que nous en pensons.

Le terme «commis», sans connotation péjorative, est encore bien vivant en français, mais son aire d'utilisation tend à se restreindre. Bénac note: «... ne se dit plus guère que de quelques employés subalternes chargés de la vente dans une maison de commerce $(\rightarrow$ Vendeur $)$, ou des écritures dans une administration ou une banque ${ }^{1} \gg$. En outre, «commis » est effectivement péjoratif dans la plupart de ses emplois: en France, «commis de culture» a été remplacé par «ouvrier agricole »; on parlera d'employé de bureau ou de vendeur, plutôt que de commis de bureau ou de magasin. (Bénac: «commis de magasin [est] vx »). «Commis» n'a plus un sens prestigieux que dans l'expression «les grands commis de l'État». Signalons au passage que «commis de magasin » avait auparavant détrôné « courtaud de boutique $\gg$.

Quant à «commis voyageur », ce terme a aussi été victime d'une dévaluation, les mots se dépréciant comme les monnaies. Le dictionnaire Robert le donne comme synonyme de représentant, mais une citation de Balzac situe son utilisation dans le temps: «Le Commis voyageur, personnage inconnu dans l'antiquité, n'est-il pas une des plus curieuses figures créées par les mœurs de l'époque actuelle ${ }^{2}$ ? Autres mœurs, autres mots... De nos jours, on a le choix entre représentant, représentant de commerce et voyageur de commerce. Bénac note que * commis voyageur » est moins usuel; nous sommes enclin à penser, comme notre lecteur, qu'il a pris une coloration péjorative.

Paul A. Horguelin

1. Henri Bénac, Dictionnaire des synonymes, Paris, Hachette, 1956.

2. Balzac, llllustre Gaudissart, cité par Paul Robert, Dictionnaire alphabétique et analogique de la langue française, Paris, Société du Nouveau Littré, 1965, vol. I, p. 843. 